\title{
POLITIK BAHASA DAN BAHASA POLITIK (Bahasa dalam Praksis Politik di Indonesia)
}

\author{
Mudjia Rahardjo
}

Doktor Sosiolinguistik Unair, Pembantu RektorIV UIN Malang

\begin{abstract}
At a glance, there is no relation between language and politics. In fact, both language and politics have mutual and equal relationship. Language is not only a means of political communication, but also a medium of political practice. As a symbolic reality; language can be used as a means to understand power dynamics and how power w'orks. Realizing the important role of language in political practice, every regime uses it as a significant instrument to carry out power consolidation by creating certain political idioms. Therefore, controlling public awareness and social collective memory through a symbolic reality alway's becomes a part of agenda of the authority to maintain their power. It is, therefore, every change of regime is always followed by the changes of new terms based on the ideology to be struggled.
\end{abstract}

Key Words: language, politics, power, authority, discourse, consolidation, elites, communication. symbolic reality.

Ulul Albab, Vol. 5 No. 1, 2004 


\section{A. Pengantar}

Sekilas, politik dan bahasa seperti dua bidang yang terpisah dan sama sekali tidak ada keterkaitan. Padahal, keduanya dapat dilihat dalam dua macam hubungan. Pertama, hubungan koordinatif. Di sini politik dan bahasa berinteraksi, saling mempengaruhi, dan tarik menarik secara setara. Kedua, hubungan subordinatif. Di sini salah satu menjadi subjek dan lainnya menjadi objek. Pada satu pihak bahasa dapat dijadikan agenda, kebijakan, dan sasaran kajian politik sehingga politik menjadi subjek dan bahasa menjadi objek; dan pada pihak lain tuturan politik dan perilaku verbal politik dapat dilihat sebagai gejala kebahasaan dan sasaran kajian kebahasaan sehingga dalam konteks ini politik menjadi objek dan bahasa menjadi subjek. Yang pertama dapat disebut politik bahasa (language politics), sedangkan yang kedua disebut bahasa politik (political language).

Politik bahasa, dengan demikian, menunjuk pada kenyataan-kenyataan di mana keberadaan, keadaan, persamaan, dan perbedaan bahasa diperpolitikkan. dituangkan, disuarakan, dan diungkapkan dalam ungkapan atau idiom kebahasaan. Sedangkan bahasa politik menunjuk pada kecenderungan bahasa elit politik atau partisipan politik, yang akan menentukan orientasi dan kecenderungan politik mereka sendiri serta orientasi dan kecenderungan politik masyarakat. Jika kita menyebut politik bahasa nasional (di) Indonesia berarti kita menunjuk pada pelbagai kenyataan di Indonesia di mana keberadaan, keadaan, persamaan, dan atau perbedaan bahasa di Indonesia diperpolitikkan oleh warga bangsa: dan keberadaan, keadaan, persamaan dan atau perbedaan politik di Indonsia yang dimainkan oleh warga bangsa diungkapkan dalam idiom kebahasaan. Sementara itu, jika kita menyebut bahasa politik nasional di Indonesia berarti kita berurusan dengan orientasi dan kecenderungan bahasa elit politik atau partisipan politik Indonesia, orientasi dan kecenderungan elit politik Indonesia yang terepresentasikan dalam bahasa, serta orientasi dan kecenderungan politik masyarakat Indonesia yang terepresentasi dalam bahasa. ${ }^{3}$

Dalam praktik sebenarnya sulit dipisahkan secara tegas antara politik bahasa dan bahasa politik. Sebab, hubungan politik bahasa dan bahasa politik sedemikian rumit. Selain itu. berbagai faktor seperti sosial, politik, kultural, ideologi, etnis, dan ekonomi turut menyemarakkan hubungan keduanya. Bisa saja persoalan kecenderungan eufemisme dan stratifikasi bahasa Indonesia susah dijelaskan dari 
segi bahasa, tapi malah bisa dijelaskan dari segi politik. Bisa saja persoalan eufemisme dan sarkasme bahasa Indonesia susah dijelaskan dari segi bahasa, tetapi juga bisa dijelaskan dari segi sosial politik. Demikian juga pelarangan pembicaraan masalah SARA, marxisme, dan negara federal pada masa Orde Baru dapat dijelaskan dari segi politik, tetapi juga bisa dijelaskan dengan baik dari segi bahasa. Ini semua menunjukkan bahwa politik bahasa sering merupakan kepanjangan tangan suatu rezim politik atau ideologi dan agenda politik suatu rezim penguasa pada satu pihak dan pada pihak lain bahasa politik sering menjadi bagian dari politik bahasa suatu rezim. ${ }^{2}$

Berdasarkan uraian di atas tampak jelas bahwa politik bahasa bukan persoalan yang sempit dan sederhana karena tidak semata-mata berurusan dengan persoalan jenis, fungsi, dan bentuk bahasa, tetapi malah jauh lebih penting dari itu politik bahasa berurusan dan menangani persoalan kehadiran bahasa, makna bahasa, wacana bahasa, ranah penggunaan bahasa, ruang penggunaan bahasa. sektor penggunaan bahasa dan sejenisnya. Hal ini mengimplikasikan bahwa politik bahasa harus diartikan pula sebagai politik lambang bahasa, politik makna, politik wacana, politik komunikasi verbal, penafsiran bahasa dalam bingkai filsafat, sosial. politik, ekonomi, etnis, budaya, demografi dan sebagainya. Geertz menyebutnya sebagai the politics of meaning. ${ }^{3}$

Tulisan ini memaparkan perkembangan kajian politik bahasa dan bahasa politik dalam praksis kekuasaan di Indonesia, diawali dengan (a) pengantar, (b) perkembangan kajian bahasa dan kekuasaan, (c) bahasa dan kekuasaan, (d) bahasa dan praktik politik di Indonesia, (e) bahasa dan konsolidasi kekuasaan, (f) konsolidasi kekuasaan Orde Baru, $(\mathrm{g})$ kontrol kekuasaan oleh masyarakat. dan (h) penutup.

\section{B. Perkembangan Kajian Bahasa dan Kekuasaan}

Dibanding bidang kajian lain, perkembangan kajian politik bahasa dan bahasa politik memperoleh minat relatif lebih kecil serta agak lambat berkembang. Belakangan lapangan kajian ini memperoleh perhatian lebih besar bukan hanya dari kalangan antropolog seperti Anderson, tetapi juga para pengkaji sosio-politikolinguistik seperti Piere Bourdieu, dan para penganut aliran pasca-strukturalis dan 
pasca-modernis seperti Michelle Foucault, Fowler, Ricoeur, Baudrillard dan lainlain.

Bahasa dan kekuasaan merupakan dua bidang yang sekilas tidak saling berhubungan. Pengamatan ini hampir benar jika bahasa diartikan sebagai tatabahasa dan kekuasaan sebagai praktik politik belaka. Paradigma demikian menyebabkan teori bahasa dan teori politik tidak bisa berjumpa. Perjumpaan bidang bahasa dan bidang kekuasaan baru mulai terjalin ketika Jean Baudrillard, Jurgen Habermas, dan Antonio Gramsci mengemukakan gagasan-gagasan mereka yang cemerlang. Baudrillard, seperti dikutip Latif dan Ibrahim menyatakan bahwa "The real monopoly is never that of technical means. but of speech". ${ }^{4}$

Ungkapan Baudrillard menegaskan pentingnya bahasa dalam praktik sosial dan politik. Bahasa memiliki kekuatan mahadahsyat untuk mengontrol perilaku individu atau masyarakat. Seseorang yang terampil mendayagunakan dan merekayasa kekuatan bahasa memiliki peluang untuk menggerakkan orang lain; demikian juga sebaliknya. Dari rumusan bahwa salah satu sifat bahasa menurut Bolinger adalah "human", maka peranan manusia menjadi pusat dari semua yang berhubungan dengan bahasa kekuasaan. "Manusialah yang dipercayai memiliki simbol-simbol kebahasaan yang unik itu, bahkan mungkin "aneh" yang dapat digunakan untuk mengatur orang lain. ${ }^{6}$

Menyangkut peran penting bahasa dalam kehidupan dan praktik sosialpolitik, jauh sebelumnya Habermas juga telah mengisyaratkan bahwa prosesproses politik tidak pernah lepas dari dari "praksis komunikasi". Habermas menekankan pentingnya aspek-aspek intersubjektivitas dalam proses wacana. Ia terutama memandang bahasa sebagai medium untuk menghubungkan sang subjek dengan tiga wilayah: wilayah eksternal, wilayah sosial, dan wilayah dunia dalam (pribadi). Wilayah pertama mengacu pada situasi di luar masyarakat di mana subjek berada, wilayah kedua mengacu pada totalitas hubungan antarpribadi yang memiliki aturan-aturan normatif dalam masyarakat, sedangkan wilayah ketiga mengacu pada totalitas dari maksud-maksud dan pengalaman subjekif sang pembicara. ${ }^{7}$ Dengan demikian, tak mengherankan jika dalam konteks hubungan bahasa dan tiga wilayah ini. Habermas menyatakan bahwa "Language is also a medium of domination and power" ${ }^{\prime \prime}$. Bahkan menurut Lorenzer bahasa bukan sekadar alat berkuasa, tetapi bahasa menyatu dengan kuasa. "Language and domination are joined together"." 
Pendapat Habermas itu memberikan pemahaman betapa kuatnya peranan bahasa dalam kehidupan berkekuasaan itu. Bahasa bukan sekadar sebagai alat komunikasi antara individu satu dengan lainnya, antara masyarakat satu dengan lainnya, lebih dari itu bahasa sering dimanfaatkan sebagai alat untuk menunjukkan adanya kekuatan-kekuatan tertentu, baik oleh perseorangan, masyarakat, organisasi kemasyarakatan, pemegang kekuasaan, dan sebagainya. Dengan demikian, betapa eratnya hubungan bahasa dengan politik. Ini sesuai rumusan Seidel, seperti dikutip Santoso, menyatakan bahwa "the case with political discourse, since the theory and practice of politics and political talk is seen to be primarily concerned with power". ${ }^{10}$

Sebaliknya, seperti dirumuskan Wareing satu cara untuk melihat bagaimana kekuasaan itu bekerja dalam masyarakat adalah melalui politik. Politik adalah penguasaan terhadap orang banyak dan alat yang efektif untuk digunakan adalah bahasa. ${ }^{11}$ Dengan demikian, dalam wacana politik akan terjadi dominasi simbolsimbol kebahasaan dari partisipan yang memiliki kekuasaan yang lebih tinggi atau besar kepada partisipan yang dikuasai, dari "penguasa" terhadap "terkuasai".

Terkait usaha penguasa mengamankan kekuasaan, menurut Louis Althusser, penguasa bisa memanfaatkan instrumen Ideological State Apparatus (ISA) dan Repressive State Aparratus (RSP). Kedua perangkat ini beroperasi untuk tujuan yang sama: melanggengkan kekuasaan, meskipun cara beroperasinya berbeda-beda. ISA beroperasi dengan cara mempengaruhi atau persuasi, sedangkan RSA beroperasi melalui cara-cara memaksa atau represif. Komponen RSA bisa berbentuk aparatur tentara, polisi, penjara, nuang tahanan, dan sebagainya. RSA melakukan tindakan-tindakan untuk mengamankan dan menjaga ISA. ${ }^{12}$

ISA meliputi berbagai aparatus ideologis seperti aktivitas keagamaan, sekolah, sistem hukum, keluarga, komunikasi, partai politik dan sebagainya. Misalnya, pengendalian ISA di masa-masa awal kekusaan Orde Baru dilakukan di antaranya melalui koorporatisme. Semua institusi yang terkait dengan keseharian masyarakat luas diorganisasikan di bawah struktur kendali terpusat dan wadah tunggal yang selalu dikontrol dan diawasi dengan ketat oleh negara. Untuk mengontrol dan sekaligus mengendalikan penuh institusi-institusi keagamaan dibentuk lembaga bernama Majelis Ulama Indonesia (MUI), untuk kendali dunia media penerbitan dibentuk Persatuan Wartawan Indonesia (PWI), untuk mengatur buruh dibentuk Serikat Pekerja Seluruh Indonesia (SPSI), dalam bidang 
kepemudaan dibentuk Komite Nasional Pemuda Indonesia (KNPI). Hal serupa juga dilakukan di lembaga-lembaga pendidikan, kebudayaan dan sebagainya.

Untuk lebih mengefektifkan dominasinya, bisa saja sebuah rezim menggunakan dua instrumen ISA dan RSA sekaligus. ${ }^{13}$ Misalnya, pada awal 1970-an, untuk menjinakkan lawan-lawan politiknya, Orde Baru memanfaatkan dua instrumen tersebut secara efektif. Selain melemparkan teror-teror ideologis seperti ekstrem kiri, ekstrem kanan, komando jihad, bersih lingkungan, bahaya laten komunis, SARA, recall, gebuk dan sebagainya, Orde Baru juga menggunakan kekuatan bersenjata sebagai ujung tombak. Ini bisa dilihat pada hampir setiap menjelang pelaksanaan pemilu tentara secara ekstensif dikerahkan untuk melakukan teror dan tindakan represif terhadap aktivis-aktivis politik yang dianggap berseberangan dengan kepentingannya. Pembentukan Opsus (Operasi Khusus) dan Kopkamtib (Komando Operasi Pemulihan Keamanan dan Ketertiban) yang memiliki kewenangan tak terbatas untuk melalukan tindakan represif, kemudian juga Bakorstanas (Badan Koordinasi Pertahanan dan Keamanan Nasional) baik di tingkat pusat maupun di daerah merupakan bukti nyata pemanfaatan aparatus RSA sebagai agen untuk mempertahankan kekuasaan Orde Baru.

Selain itu, Orde Baru juga membangun wacana "pembangunan" lewat idiom-idiom seperti stabilitas, pertumbuhan, pemerataan, pengentasan kemiskinan, regulasi dan deregulasi, modernisasi dan sebagainya. Hal yang sama juga digunakan oleh Orde Lama ketika Soekarno dengan getol mengenalkan idiom-idiom "revolusioner" nya seperti Nekolim (Neo Kolonialisme dan Imperialisme), NEFO (The New Emerging Force) yang kemudian dikonfontrasikan dengan istilah OLDEFO (The Old Emerging Force), antek kapitalis, antek imperialis, manipol, usdek, diganyang, setan kota, retooling, berdikari, indoktrinasi dan sebagainya. ${ }^{14}$

Beroperasinya bahasa kekuasaan di Indonesia juga bisa dilihat sebelum Indonesia merdeka, yakni lewat pidato Soekarno yang monumental, yakni Pidato 1 Juni 1945 di mana Sokarno atas permintaan Badan Penjelidik Usaha Persiapan Kemerdekaan Indonesia (BPUPKI) menyampaikan pidato secara heroik mengenai cita-cita dan dasar negara Indonesia merdeka kelak, yang merupakan cikal bakal kelahiran Pancasila (Dokumenta Pantja Sila Berdasarkan Adjaran Bung Kamo, 1964: 3-33). Tanggal 1 Juni 1945 yang kemudian dikeramatkan 
dikenal sebagai hari kelahiran Pancasila. Sejak saat itu Pancasila menjadi bagian tak terpisahkan dari perdebatan politis dan ideologis di Indonesia. ${ }^{15} \mathrm{Dalam}$ pidatonya Soekarno mengenalkan idiom-idiom seperti persatuan, kemerdekaan, nasionalisme, negara bangsa, musyawarah, mufakat, kesejahteraaan, gotong-royong, perjuangan, dan sebagainya. Semua ungkapan di atas tidak lain adalah bahasa politik (political language) Bung Karno sebagai siasat perjuangan politiknya. Menurut Bourdieu setiap ungkapan yang menarik perhatian masyarakat luas adalah bahasa politik. ${ }^{16}$

Praktik kekuasaan negara, yang didukung oleh aparatus ISA dan RSA yang efektif, paralel dengan konsep Gramsci tentang negara hegemonik. Menurutnya, konsep negara tersusun dari elemen institusi-institusi pemerintah dan aparat pemaksa (coersion apparatus) yang di dalamnya terdapat tentara, militer, dan lembaga hukum, serta tersusun juga oleh institusi non-pemerintahyang bertugas untuk memproduksi ideologi. Penjelasan Gramsci hampir sama dengan yang dinyatakan Althusser. Menurut Gramsci, keberhasilan dalam pengendalian secara persuasif atas massa rakyat memungkinkan aparatus represif untuk tidak perlu bertindak. Tetapi, jika tidak berhasil diperlukan tindakan represif aparat. ${ }^{17}$

Bagi Gramsci, proses hegemoni terjadi jika cara hidup, cara berpikir dan pandangan pemikiran masyarakat bawah-terutama kaum proletar-telah meniru dan menerima cara berpikir dan gaya hidup dari kelompok elit yang mendominasi dan mengeksploitasi mereka. ${ }^{18}$ Lebih dari itu, Raymond Williams menyatakan hegemoni telah berlangsung jika bukan hanya ideologi tetapi juga nilai-nilai dari golongan yang mendominasi telah diambil alih oleh secara sukarela oleh yang didominasi. $^{19}$

Dalam penanaman ideologi tersebut bahasa, terutama bahasa lokal, menjadi media sangat penting. Sebab, menurut Gramsci setiap bahasa mengandung unsurunsur budaya dan filosofi yang dipahami dan dijunjung tinggi oleh masyarakat. Sebagai realitas simbolik, bahasa mengandung makna dan nilai-nilai kultural yang berlaku dan dijunjung tinggi oleh masyarakat penggunanya. ${ }^{20}$ Itulah sebabnya mengapa para pemimpin Indonesia pascakemerdekaan-Soekarno, Soeharto, Abdurrahman Wahid-suka memproduksi idiom-idiom lokal dalam membangun wacana politik mereka. 


\section{Bahasa dan Kekuasaan}

Seperti telah diuraikan di muka bahwa setiap penguasa selalu ingin mengamankan kekuasaan yang diperolehnya. Pengamanan ini diwujudkan dalam bentuk pemertahanan, pemapanan, dan pengukuhan kekuasaan. Karena itu, setiap elit penguasa selalu terus menerus melakukan konsolidasi kekuasaan dalam segala bidang yang bersentuhan dan bergayut dengan kekuasaannya dan dalam segala cara sejauh itu efektif untuk konsolidasi. ${ }^{21} \quad$ Usaha-usaha konsolidasi tersebut umumnya tidak hanya terbatas pada bidang politik dan militer, tetapi juga merambah ke wilayah kesadaran publik. ${ }^{22}$

Secara halus dan tak kasat mata serta mungkin tak disadari, konsolidasi kekuasaan tampaknya juga dilakukan pada bidang simbol-simbol sekaligus simbolik. Karena itu, menurut Kuntowijoyo, rekayasa simbolik selalu masuk dalam program setiap kekuasaan karena penguasa tidak akan lestari di tempatnya kalau kehilangan kontrol atas dunia simbolik. Bagaimanapun simbol-simbol yang dimiliki dan beredar di masyarakat harus dikuasai supaya masyarakat atau rakyat tetap terkuasai. Tak mengherankan kalau setiap penguasa senantiasa memproduksi dan mereproduksi simbol-simbol-baik simbol verbal maupun simbol non verbalyang dapat memperkuat, memapankan, dan mengukuhkan kekuasaannya. Bersamaan dengan hal itu, penguasa selalu melakukan pengawasan atau kontrol terhadap simbol-simbol yang diproduksi dan direproduksi oleh masyarakat dan yang beredar di masyarakat. Simbol-simbol yang tidak terawasi atau terkontrol dapat membahayakan kekuasaan..$^{23}$

Kekuasaan, khususnya kekuasaan politik, tidak cukup hanya diwujudkan melalui penyederhanaan partai-partai politik, pembentukan lembaga perwakilan yang tanggap, tetapi juga melalui penguasaan ruang kesadaran dan memori kolektif masyarakat. Lewat upaya terus menerus, penguasa membangun keabsahan kekuasaannya. Upaya itu berarti pencarian basis kultural dalam masyarakat, agar kehadirannya mendapat semacam legitimasi kultural. Salah satu wilayah dunia simbolik yang tidak lepas dari jaring kekuasaan sekaligus menjadi sarana strategi hegemoni penguasa adalah BAHASA. Dalam pandangan Pabottingi $i^{24}$ dan juga Thomas." bahasa bukan semata-mata alat komunikasi penguasa kepada rakyatnya, tetapi ia juga sarana strategis untuk berkuasa. Bahasa adalah ekspresi kekuasaan, praktik bahasa menentukan bagaimana individu atau warganegara "didekte" dalam 
berbahasa. Bahasa merupakan ruang bagi pergelaran kuasa, kekuasaan terukir sejelas-jelasnya dalam bahasa. Menurut Pabottingi memilih memakai bahasa atau kata-kata tertentu menekankan pengertian tertentu atas kata, bahkan memilih dialek tertentu tak lain adalah berpolitik dalam maknanya yang paling dalam dan luas. 26

Misalnya, pada waktu unsur-unsur bahasa Jawa (Kuno) atau Kawi banyak sekali digunakan oleh penguasa untuk menamai gedung pemerintahan; pada waktu pemerintah (baca: Pusat Pembinaan dan Pengembangan Bahasa) menetapkan ejaan bahasa Indonesia, pedoman pembentukan istilah bahasa Indonesia. tatabahasa baku bahasa Indonesia, dan Bahasa Indonesia yang baik dan benar: pada waktu pemerintah memutuskan bahasa Indonesia sebagai bahasa nasional, bahasa dari luar sebagaj bahasa asing, dan bahasa lokal sebagai bahasa daerah sekaligus menetapkan kedudukan dan fungsinya masing-masing di Indonesia, sesungguhnya kita sedang menyaksikan sebuah politik bahasa di Indonesia. ${ }^{27}$

Sebaliknya, sewaktu kosa kata pembangunan, trilogi pembangunan, pertumbuhan-pemerataan-stabilitas-nasional, dan pembangunan sebagai pengamalan Pancasila serta Pancasila sebagai satu-satunya asas berbangsa, bernegara dan bermasyarakat dijadikan konsep-konsep resmi rezim Orde Baru; pada waktu gaya bahasa eufemistis, puferistis, atau sarkartis, bombastis, vulgaristis, feodalistis, dan sloganistis dijadikan sebagai gaya bahasa perintahan Orde Baru dan Reformasi Pembangunan. Pada waktu masyarakat melakukan perlawanan simbolik terhadap penguasa dengan menciptakan plesetanplesetan bahasa, misalnya Timor=Tommy Itu Memang Orang Rakus, Supersemar $=$ Suharto Persis Seperti Marcos, SDSB $=$ Soeharto Dalang Segala Bencana, Akbar Tandjung= Akhirnya Bubar Tanpa Ujung, dan sebagainya sesungguhnya kita sedang menyaksikan penggunaan bahasa politik (bahasa Indonesia) atau bahasa kekuasaan di Indonesia. ${ }^{28}$

Selain menyaksikan bahasa politik, sepanjang Orde Baru kita juga menyaksikan politik uniformasi, politik penyeragaman dan politik penunggalan. Keseragaman dan dan ketunggalan atau kesatuan dikedepankan, keragaman dan kemajemukan ditinggalkan, dalam menentukan, merumuskan dan melaksanakan format, agenda, dan kebijakan politik bahasa Indonesia. Dengan ideologi "Bahasa Indonesia yang baik dan benar" yang didukung penuh oleh Pusat Pembinaan dan Pengembangan Bahasa, yang oleh Heryanto disebut sebagai "Polkam"nya bahasa, 
keseragaman dan ketunggalan bahasa Indonesia terus menerus diupayakan melalui pelbagai sektor, jalur dan perangkat. ${ }^{29}$

Demikian juga dengan "doktrin pembinaan dan pengembangan bahasa", keseragaman dan ketunggalan bahasa Indonesia diwujudkan pada satu pihak dan pada pihak lain bahasa-bahasa tertentu dipinggirkan atau diutamakan sehingga terkesan telah terjadi marginalisasi atau dominasi bahasa-bahasa tertentu. Lebih lanjut, dengan doktrin "pembakuan bahasa", diseragamkan bahasa dan ditunggalakanlah bahasa Indonesia: kekayaan bentuk dan fungsi bahasa Indonesia diabaikan atau diingkari dengan dalih salah dan tidak baku.

Dengan demikian jelas bahwa semua ini memperlihatkan betapa kuat atau dominannnya penguasa dalam merekayasa bahasa Indonesia, sehingga tidak salah jika dikatakan bahwa politik bahasa menjadi bagian tak terpisahkan dari praktik kepolitikan Indonesia. Dengan dominannya rekayasa bahasa sebagai "mesin atau buldoser" politik penyeragaman dan penunggalan bahasa Indonesia tersebut, terkuburlah keragaman dan kemajemukan bahasa Indonesia. Di sini kemajemukan dan keragaman dilecehkan, tidak dihormati dalam format dan agenda politik bahasa Indonesia. Secara tidak langsung hal ini mengakibatkan keseragaman daya dan kemampuan ungkap bahasa-bahasa di Indonesia termasuk bahasa Indonesia selain keseragaman pola pikir masyarakat Indonesia.

Menurut Nurcholish Madjid, praktik hegemonisasi atau penyamarataan oleh penguasa Orde Baru tanpa sadar telah mengingkari jati diri Indonesia sebagai sebuah bangsa pluralistik. Penyeragaman berbagai aspek budaya (termasuk di dalamnya adalah bahasa sebagai inti kebudayaan) yang akhimya melahirkan istilah "budaya nasional (?)" dan pemberlakukan sistem pemerintahan yang seragam dengan meniadakan hal-hal yang berbau lokal merupakan bukti konkret bagaimana penguasa Indonesia telah mengingkari prinsip bhineka tunggal ika dan bahkan membunuhnya pelan-pelan. Idiom-idiom lokal Jawa yang berbunyi ing ngarso sung tulodho, ing madyo mangun karsa, tutwuri dandayani (di depan menjadi memberi teladan, di tengah membangun semangat, di belakang memberi dukungan) adalah contoh nyata bagaimana Orde Baru melakukan praktik homogenisasi secara luar biasa. Menurutnya, praktik homogenisasi seperti itu sangat berbahaya, karena hal itu sama saja dengan praktik meniadakan pluralisme-satu hal yang sebenarnya menjadi ciri keindonesiaan kita. PJuralisme baru tetap eksis jika ada pengakuan 
atas berbagai keanekaragaman. Jika Indonesia secara konsekuen mengakui prinsip bhineka tunggal ika, mengapa takut dengan adanya berbagaj perbedaan? ${ }^{30}$

\section{Bahasa dan Praktik Politik di Indonesia}

Berbicara tentang bahasa Indonesia sebagai piranti praktik politik Indonesia kontemporer, dengan mengutip sejarawan Swiss terkemuka Herbert Luethy dan Anderson, mengungkapkan bahwa bahasa Indonesia kontemporer merupakan bahasa sintesis yang meminjam semua terminologi asing dengan melimpah sehingga sulit dimengerti oleh orang Indonesia pada umumnya. Pidato-pidato politik pemimpin Jawa menunjukkan istilah irasional yang muluk-muluk yang mengekspresikan obsesi elit Jawa yang kehilangan kepribadiannya. Para elit politik Indonesia kontemporer menyadari pentingnya bahasa Indonesia baru bukan hanya sebagai alat komunikasi yang dapat mengekspresikan tidak hanya nasionalisme Indonesia melainkan juga aspirasi Indonesia, tradisi Indonesia dan realitas-realitas internasional. ${ }^{31}$

Kendati bahasa Indonesia telah memulai peran pentingnya sejak 1920-an, baru pada saat pendudukan Jepang bahasa Indonesia secara formal menjadi bahasa negara untuk diajarkan di sekolah-sekolah dan menjadi bahasa birokrasi. Selama masa revolusi 1945-1949, bahasa Indonesia menjadi bahasa perlawanan untuk menolak kembalinya Belanda dan juga bahasa pengharapan untuk masa depan Indonesia. Masa ini merupakan masa pengisian bahasa Indonesia dengan kosakata yang menggetarkan secara emosional, seperti merdeka, rakjat, perjuangan, pergerakan, kebangsaan, kedaulatan, semangat, dan revolusi. Hampir semua kata emosional bahasa Indonesia berhubungan dengan perjuangan dan kekerasan fisik revolusi dan memiliki konotasi heroik-politis.

Di tengah semakin memudarnya dorongan revolusioner di kalangan elit pasca-revolusi, menurut Anderson, terjadi Jawanisasi bahasa Indonesia melalui:

a. Kramanisasi bahasa publik Indonesia. Ketika Melayu revolusioner semakin dikikis oleh berbagai peristiwa, bahasa Indonesia cenderung semakin menjadj bahasa sopan-santun politik yang kefasihan penggunanya akan menunjukkan stratifikasi sosialnya di masyarakat. Penguasaan kosakata krama juga semakin penting bagi elit politik. 
b. Ngoko baru. Kata-kata ngoko Jawa menembus bahasa Indonesia pada semua tingkatan, seperti ganyang, krumus, gontok-gontokan, nggrogoti, bobrok, plintat-plintut dan sebagainya. Ini mencerminkan pertumbuhan kekuasaan Jawa, khususnya pada Presiden Sukarno sebagai sumber utama politik sejak 1959.

c. Netralisasi atau pengurungan simbol-simbol revolusioner. Proses ini dilakukan dengan menguburkan kata-kata yang memiliki kekuatan simbolik yang besar seperti revolusi, sosialisme dan demokrasi.

d. Gaya topeng, yakni gaya bahasa yang mengutamakan penghalusan semantik secara berlebihan sehingga semua kedengaran dan terasa baik, tetapi kebenaran yang sesungguhnya tertutupi. Gaya bahasa topeng menunjukkan bahwa permainan politik Indonesia diwarnai oleh imaji tentang topeng dan wayang dengan konsepsi bahwa segala sesuatu ada "di belakang layar". Penampilan publik seorang tokoh politik selalu ditanggapi dengan kepercayaan yang dalam hal tertentu hanya bermain topeng. Ini tampak pada kosakata bahasa politik Indonesia yang semakin didominasi oleh kata-kata yang secara tersirat dan tersurat menghadirkan imaji tersebut, misalnya dalang, mendalangi, wayangnya, lakon, gara-gara, perang tanding, jejer, Bratayuda, Durna adalah kata-kata politik yang diambil dari dunia pewayangan. Bersamaan dengan itu, ide tentang topeng semakin menjadi ide tentang penyamaran makna dengan maksud menyembunyikan kebenaran di balik sebuah ungkapan.

e. Eufemisasi bahasa Indonesia. Berbeda dengan gaya topeng, eufemisme tidak menutupi kebenaran, tetapi hanya mengubah cara pengungkapan makna untuk menghindarkan ketersinggungan atau ketidaksopanan yang mungkin dirasakan oleh pendengar atau pembaca, seperti istilah rawan pangan, diamankan, masyarakat kurang beruntung, penyesuaian harga, dimintai keterangan dan sebagainya. Tak pelak eufemisme dipandang sebagai andalan politik makna penguasa Orde Baru. ${ }^{32}$

\section{E. Bahasa dan Konsolidasi Kekuasaan}

Secara kasar dan umum uraian di atas mengisyaratkan bahwa konsolidasi kekuasaan oleh penguasa melalui bahasa berlangsung efektif, meskipun mungkin 
secara tidak sadar dan tidak terancang secara berencana. Konsolidasi kekuasaan melalui bahasa sebenarnya dilakukan penguasa di beberapa negara, seperti di Malaysia, Filipina, India dengan taraf keberhasilan berbeda-beda.

Filipina gagal menetapkan bahasa Tagalog sebagai bahasa persatuan sehingga penguasa Filipina menemui kesulitan mengkonsolidasikan kekuasaan melalui bahasa. Demikian juga India tidak berhasil mendesakkan salah satu bahasa local untuk dijadikan bahasa nasional sehingga tidak bisa melakukan konsolidasi kekuasaan melalui bahasa. Malaysia cukup berhasil mengkonsolidasikan kekuasaan melalui bahasa karena penguasa berhasil "memalaysiakan" bahasa Melayu tanpa menimbulkan pergolakan.

Dalam sejarah kita sendiri, konsolidasi melalui bahasa dapat dikatakan berhasil tanpa menimbulkan pertikaian politis berarti. Mungkin tidak disadari masyarakat atau memang masyarakat tidak berani mendebat meskipun sadar. Para penguasa Mataram II, Orde Lama, dan Orde Baru berhasil melakukan konsolidasi kekuasaan melalui bahasa tanpa mengalami banyak hambatan dan tantangan dari masyarakat.

Raja-raja Mataram II khususnya Sultan Agung melakukan konsolidasi kekuasaan melalui bahasa secara sadar dan berencana. Mereka mencoba mengembangkan unggah-ungguhing basa Jawa untuk menciptakan jarak sosial antara raja dan rakyat agar keagungbinataraan raja-raja Mataram Il bisa meningkat. Meningkatnya keagungbinataraan berarti semakin kukuhnya dinasti Mataram II. Hal ini menyiratkan pula betapa kekuasaan dinasti Mataram II terkonsolidasi secara baik tanpa menimbulkan pergolakan dalm masyarakat.

Sewakiu penguasa Orde Lama memegang kekuasaan, konsolidasi kekuasaan melalui bahasa Indonesia dilakukan melalui beberapa hal. Pertama, untuk mengeliminasi dan menghancurkan kekuatan yang mengancam kekuasaannya. diciptakan istilah-istilah seperti antirevolusi, ganyang, sikat, gilas, kontra-revolusi dan semacamnya. Dengan kata-kata itu diharapkan muncul pengertian yang bisa menyudutkan kekuatan oposisi dan menggalang kekuatan untuk menghancurkan kekuatan oposisi.

Selain itu, untuk menggalang dan memperkukuh kekuatan-kekuatan yang mampu mengkonsolidasikan kekuasaan, penguasa Orde Lama menciptakan istilahistilah jubị usman, menipol udek, djarek (djalannya revolusi kita) revolusi belum selesai, berdikari (berdiri di atas kaki sendiri), nasakom (nasionalisme, Islam, dan 
komunisme) dan sebagainya. Dua contoh di atas menunjukkan bahwa dalam tradisi perpolitikan kita konsolidasi kekuasaan oleh penguasa dengan menggunakan bahasa Jawa dan bahasa Indonesia terbukti cukup efektif untuk memperkukuh kekuasaan. Itulah sebabnya, politik bahasa dan bahasa politik selalu menjadi proyek bawah sadar setiap rezim penguasa demi kelangsungan kekuasaannya. ${ }^{33}$

\section{F. Konsolidasi Kekuasaan Orde Baru}

Sebagaimana diketahui, Orde Baru memegang kekuasaan dengan memperkenalkan idiom "pembangunan" kepada seluruh masyarakat Indonesia. Pembangunan dimaksudkan untuk menciptakan kemakmuran dan kesejahteraan rakyat. Tumpuannya ialah pemerataan, petumbuhan, dan stabilitas. Pelaksanaanny a secara bertahap dan berkesinambungan yang selanjutnya dikenal dengan pelita. Dengan demikian, pembangunan merupakan proyek utama Orde Baru selama memegang kekuasaan. Agar kekuasaannya terjamin dan aman sehingga bisa melaksanakan proyek pembangunannya, para penguasa Orde Baru senantiasa berusaha mewujudkan keterjaminan dan keamanan kekuasaan dengan cara terus-menerus melakukan konsolidasi kekuasaan. Meskipun bukan merupakan kegiatan yang terencana secara khusus dan terbuka, konsolidasi ini salah satunya dilakukan melalui bahasa (Indonesia).

Konsolidasi kekuasaan melalui bahasa Indonesia ini dilakukan dengan berbagai cara. Pertama, dengan menghaluskan konsep-konsep dan pengertianpengertian yang bersentuhan dengan kekuasaan yang terkandung dalam bahasa Indonesia. Penghalusan dimaksudkan untuk melenyapkan konsep dan pengertian yang membahayakan kekuasaan Orde Baru dan untuk menciptakan citra baik Orde Baru kepada masyarakat. Istilah-istilah seperti masa bakti, purna tugas, rawan pangan, kekurangan gizi, penyesuaian harga dan sebagainya merupakan contoh upaya penciptaan citra baik penguasa Orde Baru sekaligus pelenyapan konsep dan pengertian yang membahayakan kekuasaannya.

Kedua, dengan cara pengasaran konsep-konsep dan pengertian yang bersentuhan dan berhubungan dengan kekuasaan yang terkandung dalam bahasa Indonesia. Umumnya pengasaran ini dilakukan untuk menangkal dan menyudutkan kekuatan lain yang bisa mengancam kekuasaan Orde Baru, seperti istilah-istilah SARA, GPK, Subversi, OT, OTB dan sebagainya. Istilah-istilah tersebut 
mempunyai dampak luar biasa jika ditujukan kepada kelompok atau golongan tertentu.

Ketiga, dengan memproduksi konsep-konsep dan pengertian-pengertian yang bisa mengerem dan menurunkan emosi masyarakat sewaktu berhadapan dengan realitas tertentu yang tidak cocok dengan pandangannya, misalnya istilah jer basuki mawa bea, mikul duwur mendem jero, demi kepentingan umum, demi pembangunan, mengetatkan ikat pinggang dan sebagainya.

Keempat, dengan cara memproduksi atau mempopulerkan konsep-konsep dan pengertian-pengertian yang bisa merangkul dan menyedotkan perhatian dan energi masyarakat untuk melaksanakan program pembangunan yang telah dirancang Orde Baru, misalnya istilah-istilah seperti pembangunan, partisipasi, dari, oleh dan untuk masyarakat, persatuan dan kesatuan bangsa dan sebagainya.

Kelima, dengan cara penyeragaman bahasa atau istilah-istilah yang dipakai pejabat-pejabat. Elit penguasa Orde Baru sangat menekankan kesatuan bahasa pejabat atau aparatnya. Penekanan kesamaan bahasa berarti penekanan kesamaan konsep dan pengertian. Bila hal ini berhasil dilaksanakan, konflik-konflik dan perbedaan-perbedaan pendapat yang bisa merawankan kekuasaan dapat dieliminasi atau disingkirkan. Dalam kenyataan, elit penguasa Orde Baru berhasil melaksanakan penyeragaman bahasa pejabat sehingga ketegangan-ketegangan dan kesalahpahaman dapat dihindarkan, bahkan semua kekuatan aparat bisa dikontrol dengan baik. Kita perhatikan betapa seringnya penguasa Orde Baru memproduksi istilah-istilah seperti keterbukaan, Pancasila sebagai ideologi terbuka, demi kepentingan umum, adil dalam kemakmuran dan makmur dalam keadilan, memasyarakatkan olah raga dan mengolahragakan masyarakat dan sebagainya.

Keenam, dengan cara feodalisasi bahasa Indonesia. Bahasa Indonesia yang kita pakai sekarang semakin feodal, bukannya egaliter dan demokratis. Taraf feodal ini sangat tinggi dibanding dengan masa-masa sebelumnya, seperti masa perjuangan merebut kemerdekaan. Pada masa itu digunakan istilah "bung" untuk menyapa pemimpin, misalnya Bung Tomo, Bung Karno, Bung Hatta dan Bung Syahrir. Istilah-istilah itu semasa Orde Baru hilang dan diganti dengan "bapak" diikuti dengan kata-kata yang menunjukkan feodalisme, seperti berkenan, memohon restu, memohon petunjuk, dihaturkan dan sebagainya. Makin 
feodalnya bahasa Indonesia ini berarti makin feodalnya kita berhubungan atau berkomunikasi. Ini mengakibatkan jarak sosial yang lebar antara masyarakat dan penguasa. Jarak sosial yang lebar tentu menguntungkan Orde Baru karena pelaksanaan kontrol kekuasaan menjadi lebih mudah.

\section{G Kontrol Kekuasaan oleh Masyarakat}

Memperhatikan perjalanan praktik politik Indonesia, disadari bahwa penguasa Orde Baru mampu mengamankan dan mengkonsolidasikan kekuasaan dengan baik, tidak hanya melalui tindakan-tindakan politis, keamanan, dan birokrasi melainkan juga melalui penguasaan simbol-simbol (baca: bahasa) sebagaimana diuraikan di atas. Keberhasilan melakukan konsolidasi ini membuat penguasa Orde Baru bisa terus melaksanakan proyek besar bernama pembangunan.

Dalam melaksanakan pembangunan, kekuarangan-kekurangan dan eksesekses negaif muncul. Korupsi, koneksi, penyelewengan jabatan, jurang kaya miskin, ketidakadilan sosial dan sebagainya merupakan penyakit-penyakit yang muncul selama pembangunan dilaksanakan meskipun mungkin benih-benihnya sudah ada, bahkan merajalela sejak Orde Lama. Hal ini menunjukkan bahwa kekuasaan Orde Baru pun memiliki kekurangan-kekurangan di samping keberhasilankeberhasilan bagi masyarakat. Pertanyaan kita bagimana masyarakat Indonesia mengontrol kekurangan-kekurangan kekuasaan Orde Baru ini melaui bahasa Indonesia.

Ada dua cara utama masyarakat melakukan kontrol kekuasaan Orde Baru. Pertama, penyelewengan akronim-akronim yang maknanya sudah baku bagi kita khususnya elite penguasa Orde Baru, misalnya istilah posyandu dipanjangkan sebagai pos doyan duit. Oleh masyarakat kantor-kantor dan lembaga yang dilanda korupsi lazimnya disebut posyandu itu. Padahal oleh pemerintah istilah itu diartikan sebagai pos pelayan terpadu yang berhubungan dengan kesehatan. Akronim KORPRI oleh masyarakat dianggap kependekan dari koruptor pribumi karena masyarakat melihat banyaknya korupsi dan koruptor yang tidak tertangani, malahan dibiarkan membeku. Padahal, sebagaimana kita ketahui, KORPRI arti bakunya Korps Pegawai Republik Indonesia. Demikian juga akronim Bakortanas diselewengkan menjadi Bahaya Korupsi Sudah Tarap Nasional, SDSB diselewengkan menjadi Sama Dengan SeBelumnya, Waskat diselewengkan 
menjadi Wajib Saya Sikat, Sidak diselewengkan menjadi KomiSI MenDAK, BCA diselewengkan menjadi Gagal Bangun Hebatnya Negeri, dan KPR BTN diselewengkan menjadi Kelompok Pemiskin Rakyat, Bunga Terus Naik. ${ }^{34}$

Penyelewengan-penyelewengan akronim di atas merupakan gejala arus bawah, bukan arus atas. Karena itu, semua itu lebih banyak kita jumpai dalam kasak kusuk, pembicaraan tak resmi, dan kalangan terbatas. Mengapa gejala tersebut berada diarus bawah? Ada dua hal kemungkinan. Kemungkinan pertama, masyarakat tidak berani mengungkapkan secara terbuka karena risikonya besar sekali bagi dirinya. Kemungkinan kedua, Masyarakat tidak mendapat saluran untuk melakukan kontrol atas kekurangan-kekurangan yang ada meskipun dulu kita kenal ada Tromol Pos 5000. Ini berarti tersumbatnya saluran kontrol masyarakat terhadap kekuasaan Orde Baru. Dua hal kemungkinan ini sebenarnya mengisyaratkan agar elit penguasa Orde Baru untuk lebih menjamin masyarakat yang melakukan kontrol kekuasaan'Orde Baru dan memberikan saluran kontrol yang lancar, jelas, dan efektif.

Kedua, pemelesetan konsep-konsep dan pengertian-pengertian yang sudah baku dalam bahasa Indonesia. Dalam hubungan ini masyarakat melakukan pemaknaan sendiri atas suatu konsep dan pengertian bahasa Indonesia. Mereka membelot, tidak mau mengikuti konsep dan pengertian yang baku. Sebagai contoh. masyarakat yang sedang dilanda kecemasan karena penggusuran rumah dengan ganti rugi tidak memadai. Masyarakat dalam hal ini merupakan pihak yang tidak pernah diuntungkan sehingga mereka berseloroh: "Namanya saja ganti rugi, meskipun diganti ya tetap rugi. Kalau namanya ganti untung barulah kita bisa untung kalau digusur!" Menurut Ayatrohaedi istilah itu mestinya diganti menjadi ganti untung atau ganti laba. ${ }^{35}$ Demikian juga istilah demokrasi sering diselewengkan menjadi demo kerasi yang maksudnya kalau ada demonstrasi selalu dikerasi! Menurut Saryono, pemelesetan konsep dan pengartian baku semacam ini merupakan sinisme masyarakat terhadap realitas yang ada. Ini merupakan bentuk kontrol masyarakat atas kekuasaan Orde Baru meskipun kontrol-kontrol semacam ini mungkin tidak berarti. ${ }^{36}$

Mengapa masyarakat kita melakukan sinisme dalam bentuk pemelesetan konsep-konsep dan pengertian-pengertian baku dalam bahasa Indonesia? Ada beberapa kemungkinan. Kemungkinan pertama, masyarakat kurang mendapat perlindungan secara memadai bila mendapat musibah tertentu, misalnya 
penggusuran dan penangkapan. Umumnya mereka dalam posisi lemah dan dilemahkan. Kemungkinan kedua, masyarakat tidak mendapatkan saluran memadai untuk mengadukan nasibnya. Meskipun sudah ada berbagai lembaga bantuan hukum dan Tromol Pos 5000, namun mereka mungkin kurang mendapatkan pelayanan memadai yang bisa meringankan nasibnya. Sebaliknya justru memperoleh ancaman dan gangguan yang pasif. Kemungkinan lain, masyarakat kita sudah benar-benar putus asa, apatis, dan jengkel atas janji-janji dan tindakan-tindakan yang diharapkan dapat membantu derita mereka. Itu terjadi, mungkin karena realitasnya tidak ada atau tak bermanfaat. Agar mereka tetap waras dan sehat pikiran, kemudian mencoba menyalurkan keputusasaan, keapatisan, dan kejengkelannya melalui sinisme. Mereka mencoba menghumorkan penderitaan mereka sendiri di bawah kekuasaan Orde Baru.

Itu semua sebenarnya merupakan cermin kontrol masyarakat yang sudah tidak berdaya terhadap kekuasaan Orde Baru. Elit penguasa Orde Baru hendaknya menyadari bahwa pemelesetan tersebut merupakan pembangkangan masyarakat terhadap simbol-simbol verbal bahasa Indonesia yang sudah dibakukan. Jika hal ini dibiarkan berlarut-larut niscaya terjadi miskomunikasi antara masyarakat dan elit penguasa Orde Baru. Malahan mungkin terjadi keterputusan komunikasi. Pelesetan, menurut Heryanto, adalah piranti perlawanan simbolik dan ekspresi kejengkelan masyarakat lapis bawah terhadap penguasa yang dianggap gagal menjalankan misi dan memenuhi tuntutan masyarakat. ${ }^{37}$

Dalam tradisi Jawa, orang Jawa cenderung menghindari konflik secara frontal dengan orang lain, namun tetap senang melakukan kritik walau tak langsung. Melalui pelesetan sebenarnya masyarakat melakukan kritik pedas yang intinya bernada harapan agar penguasa memperhatikan masyarakat lapis bawah. ${ }^{38}$ Dengan demikian, pelesetan tidak bisa diartikan sekadar permainan kata atau akrobatik kata untuk menjungkirbalikkan kebenaran menjadi ungkapan konyol sehingga kata kutukan dan umpatan dijungkirbalik menjadi ungkapan gagah dan terhormat. Tetapi, pelesetan harus dipahami sebagai bentuk perlawanan simbolik masyarakat melawan penguasa.

Kritik terhadap penguasa memang masih mungkin, tetapi tidak dinyatakan dengan tidak langsung, apalagi dengan cara membentuk kekuasaan tandingan. Semua kritik yang menunjukkan ciri-ciri kekuasaan tandingan pasti akan dibasmi. Menurut Anderson, kritik dapat dinyatakan oleh para petapa atau para resi, yang 
jelas menunjukkan mereka tidak tertarik pada kekuasaan duniawi. Kritik bisa dinyatakan oleh para punakawan, badut istana, dalam bentuk lelucon lewat pertunjukan kesenian rakyat seperti ludruk, ketoprak, drama dan sejenisnya. ${ }^{39}$ Menurut Nas, berbagai bentuk lelucon terhadap simbol-simbol resmi negara terutama berkembang subur di masyarakat yang sangat tertekan oleh dominasi penguasa. ${ }^{40}$

\section{H. Penutup}

Selama tiga dasar warsa terakhir, bahasa telah menjadi bagian penting kajian ilmu-ilmu sosial seperti sosiologi, ilmu politik, ilmu komunikasi, filsafat, psikologi di samping linguistik. Batas masing-masing ilmu sosial tersebut juga semakin tipis. Dalam kajian ilmu politik, bahasa memiliki posisi sangat penting, sebab antara bahasa dan politik terjadi hubungan tarik menarik dan saling mempengaruhi secara setara. Praktik politik terukir secara jelas dalam bahasa. Pun juga bahasa sering dijadikan agenda dan kebijakan elit penguasa dalam rangka melakukan konsolidasi kekuasaan.

Itu sebabnya, setiap rezim penguasa selalu berusaha menciptakan idiomidiom politik yang "khas" untuk kelangsungan kekuasaannya sesuai ideologi yang diperjuangkan. Karena itu, setiap pergantian elit penguasa selalu mengandung implikasi pergantian "bahasa". Pergantian "bahasa" itu dapat dilihat pada dua aspek, yakni pergantian daftar kosakata dan pergeseran makna kata. Misalnya, kosakata Orde Lama berpusat pada kata kunci "revolusi". Indonesia digambarkan sebagai sebuah negara yang sedang melakukan revolusi besar untuk membangun dunia baru dan menjungkirbalikkan dunia yang sekarang. Orang atau kelompok yang tidak menyetujui "revolusi" dinamakan kelompok antirevolusi.

Sementara kosakata Orde Baru berpusat pada kata kunci "pembangunan". Indonesia digambarkan sebagai bangsa yang sedang membangun. Karena itu, kosakata yang diciptakan selalu bernuansa "pembangunan". Orang atau kelompok yang tidak setuju pembangunan disebut "antipembangunan". Demikian juga Pasca Orde Baru, di mana demokratisasi, reformasi dan transparansi menjadi tuntutan masyarakat luas, bahasa Indonesia juga dihiasi dengan kosakata-kosakata tersebut. 
Pergantian idiom-idiom politik yang dilakukan oleh setiap rezim penguasa tersebut tiada lain merupakan politik makna demi kepentingan ideologi politik yang diperjuangkan. Bahasa bukan saja monopoli penguasa sebagai piranti konsolidasi kekuasaan, tetapi juga masyarakat yang tak berkuasa. Lewat bahasa masyarakat melakukan perlawanan simbolik terhadap penguasa dengan cara menciptakan pelesetan-pelesetan dari idiom-idiom ciptakan penguasa.

Wal hasil, disadari atau tidak bahasa (bahasa Indonesia) telah menjadi proyek bawah sadar setiap rezim penguasa demi kepentingan kekuasaanya dan karenanya telah pula menjadi bagian penting praktik politik Indonesia kontemporer.[]

\section{Endnotes}

1 Djoko Saryono, "Bahasa sebagai Pusat Keberadaan Manusia", dalam Basis Edisi Maret 1993, hal. 3.

2 Djoko Saryono, Ibid, 1993, hal. 3.

3 Clifford Geertz. The Interpretation of Cultures ( New York: Basic Books, 1973), hal. 331

4 Yudi Latif dan Ibrahim (Eds.) "Prolog Bahasa dan Kekuasaan: Politik Wacana di Panggung Orde Baru", dalam Yudi Latif dan Ibrahim (Eds.), Bahasa dan Kekuasaan : Politik Wacana di Panggung Orde Baru. (Bandung: Mizan, 1996), hal, 15.

5 Bolinger, Language-The Loaded Weapon: The Use and Abuse of Language Today. London: Longman Group Limited, 1981), hal. 2.

- Santoso, Penggunaan Bahasa Indonesia dalam Wacana Politik. Disertasi Program Doktor Universitas Negeri Malang, Program Studi Pendidikan Bahasa tahun 2001. hal. 67.

7 Widharyanto, Manifestasi Perspektif Surat Kabar Indonesia pada Akhir Era Orde Baru ke Dalam Strategi Penyajian Informasi dan Bentuk-Bentuk Ekspresi Bahas, Disertasi Program Doktor Universitas Negeri Malang, 2000, hal. 41.

* Yudi Latif dan Ibrahim, Op. Cit, hal. 16.

9 Bleicher, Josef. Contemporary Hermeneutics: Hermeneutics as Method, Philosophy, and Critique. (London, Boston and Henley: Routledge \& Kehan Paul, 1980), hal. 170.

10 Santoso, Op. Cit. hal. 66. 
1 Shan Wareing, "What is Language and What does It do?", in Linda Thomas and Shan Wareing (Eds.), Language, Sociery and Power. (London and New York: Routledge 1999), hal. 11.

12 George Ritzer, Sociological Theory. (McGraww-Hill INC 1992), hal. 296-299; bdk. Malcom Waters, Modern Sociological Theory! (London, Thousand Oaks, New Delhi: SAGE Publications 1994), hal. 234.

13 Malcom Waters, Ibid, 235.

14 Santoso, Op. Cit., hal. 10; bdk. Khamami Zada (Ed.), Neraca Gus Dur di Panggung Kekuasaan (Jakarta: LAKPESDAM 2002), hal. 12.

1: Douglas E. Ramage, Politics in Indonesia: Democracy, Islam and the Ideology of Tolerance, (London and New York: ROUTLEDGE, 1995), hal. 3.

it Pierre Bourdieu, "Structures, Habitus, Power: Basis for a Theory of Symbolic Power" in Nicholas B. Dirks et. al (eds.)., Culture/Power/History: A Reader in Contemporary Social Theory. Princeton, (New Jersey: Princeton University Press, 1994), hal. 165.

17 Roger Simon, Gagasan-Gagasan Politik Gramsci. Terj. Kamdani dan Imam Baehaqi. (Yogyakarta: INSIST, 1999), hal. 86-99.

is Mansour Fakih, "Masyarakat Sipil dan Perubahan Sosial di Indonesia: Sebuah Agenda", dalam Muhammad Hidayat Rahz (ed.), Menuju Masyarakat Terbuka. (Yogyakarta: ASHOKA INDONESIA bekerjasama dengan INSIST. 1999), hal. 17.

14 Geoff Eley, "Nations, Publics, and Political Cultures: Placing Habermas in the Nineteenth Century", in Nicholas B. Dirks et. al (eds.).. Culture/Power/History: A Reader in Contemporan Social Theory. (Princeton, New Jersey: Princeton University Press, 1994), hal. 321.

20 Warsono, Wacana Politik Kiai NU pada Era Pemerintahan Gus Dur: Apakah Sebagai Intelektual Organik atau Intelektual Tradisional? Disertasi Program Pascasarjana Universitas Airlangga, 2002, hal.32.

2) Djoko Sarjono, Op. Cit. hal. 2; bdk. Moedjanto, G. "Konsolidasi Kekuasaan Dinasti Mataram Lewat Pengembangan Bahasa Jawa", Basis, No. 7-8 Tahun XXXIV, 1985. hal.41.

22 Eriyanto, Kekuasaan Otoriter: Dari Gerakan Penindasan Menuju Politik Hegemoni. Studi atas Pidato-Pidato Politik Soeharto. (Yogyakarta: INSIST, 2000), hal. 63 .

23. Eriyanto, Ibid, hal. 63.

24 Mochtar Pabottingi, "Komunikasi Politik dalam Transformasi Ilmu Politik", Prisma, No. 6 Tahun XX, 6 Juni 1991, hal. 3.

25. Thomas, Linda, and Shan Wareing. Language, Sociery and Pover. (New York: Routledge, 1999), hal. 11. 
26 Mochtar Pabottinggi "Bahasa, Politik, dan Otosentrisitas" dalam Yudi Latif dan Ibrahim, I.S. (Eds.)., Bahasa dan Kekuasaan : Politik Wacana di Panggung Orde Baru. (Bandung: Penerbit Mizan, 1996), hal. 213.

27 Hasan Alwi, . "Fungsi Politik Bahasa", Politik Bahasa. (Jakarta: Pusat Bahasa, Departemen Pendidikan Nasional, 2000), hal. 6.

28 Djoko Saryono, "Menghormati Keberagaman, Meneguhkan Keindonesiaan: Politik Bahasa di Tengah Kemajemukan Bangsa", Makalah pada Lokakarya Politik Bahasa di Jakarta , 2000, hal. 3.; lihat, Ariel Heryanto “ Bahasa dan Kuasa: Tatapan Postmodernisme”, dalam Yudi Latif dan Ibrahim, I.S. (eds.), Op. Cit. Hal. 102.

29 Ariel Heriyanto, Ibid, hal. 252.

30) Kompas, 23/3/2000: 9.

31 Anderson. Language and Power: Exploring Political Cultures in Indonesia. (Ithaca and London: Cornell University Press, 1990), hal. 123.

32 Benedict R. O`G Anderson, Kuasa-Kata: Jelajah Budaya-Budaya Politik di Indonesia. Terj. Revianto Budi Santosa. (Yogyakarta: MATABANGSA, 2000. ), hal. 310.

33. Djoko Saryono, Op. Cit., Hal. 3

${ }^{34}$ Djoko Saryono, Ibid, hal. 8.

35. Ayatrohaedi. "Ganti Rugi", dalam Kompas, 28/12/2002, hal. 12

36 Djoko Saryono, Op. Cit. hal. 8.

37 Ariel Heryanto, Op. Cit., hal 102.

38 Kompas, 14/7/2000.

34 Arief Budiman, Budiman, Arief. 1987. "Kebudayaan Kekuasaan atau Sosiologi Kekuasaan?", Prisma No. 3 Tahun XVI Maret 1987, hal. 66; bdk. Budi Susanto, Ketoprak: The Politics of the Past in the Present Day of Java. (Yogyakarta: Penerbit Kanisius, 1997).

40 Peter J.M. Nas, "Tatanan Simbolik Jakarta: Dari Kosmos ke Kondominium", JIIS Jurnal Ilmu-Ilmu Sosial No.4: Perubahan Kelembagaan Menjelang Tahun 2000. (Jakarta: Pusat Antar Universitas bidang Ilmu-Ilmu Sosial Universitas Indonesia (PAUIS-UI) dengan Penerbit Gramedia Pustaka Utama. 1993), hal. 60. 


\section{Bibliography}

Alwi, Hasan (Ed.). 2000. "Fungsi Politik Bahasa", Politik Bahasa. Jakarta: Pusat Bahasa, Departemen Pendidikan Nasional

Anderson. 1990. Language and Power: Exploring Political Cultures in Indonesia. Ithaca and London: Comell University Press.

Anderson, Benedict R. O'G. 2000. Kuasa-Kata: Jelajah Budaya-Budaya Politik di Indonesia. Terj. Revianto Budi Santosa. Yogyakarta: MATABANGSA Ayatrohaedi. 2002. "Ganti Rugi", dalam Kompas, 28/12: 12:

Bleicher, Josef. 1980. Contemporary Hermeneutics: Hermeneutics as method, philosophy, and critique. London, Boston and Henley: Routledge \& Kehan Paul

Bolinger, D. 1980. Language-The Loaded Weapon: The Use and Abuse of Language Today. London: Longman Group Limited

Bourdieu, Pierre. 1994. "Structures, Habitus, Power: Basis for a Theory of Symbolic Power" in Nicholas B. Dirks et. al (eds.)., Culture/Power/ History: A Reader in Contemporary Social Theory. Princeton, New Jersey: Princeton University Press

Budiman, Arief. 1987. "Kebudayaan Kekuasaan atau Sosiologi Kekuasaan?", Prisma No. 3 Tahun XVI Maret

Dokumenta Pantja Sila Berdasarkan Adjaran Bung Karno.1945. Dari Lahirnya Pantja-Sila Sampai Tjamkan Pantja Sila. Djakarta.

Eley, Geoff. 1994. "Nations, Publics, and Political Cultures: Placing Habermas in the Nineteenth Century", in Nicholas B. Dirks et. al (eds.)., Culture/Power' History: A Reader in Contemporary Social Theory. Princeton, New Jersey: Princeton University Press

Eriyanto. 2000. Kekuasaan Otoriter: Dari Gerakan Penindasan Menuju Politik Hegemoni. Studi atas Pidato-Pidato Politik Soeharto. Yogyakarta: INSIST

Fakih, Mansour. 1999. “Masyarakat Sipil dan Perubahan Sosial di Indonesia: Sebuah Agenda", dalam Muhammad Hidayat Rahz (ed.), Menuju Masyarakat 
Terbuka. Yogyakarta: ASHOKA INDONESIA bekerjasama dengan INSIST

Geertz, Clifford. 1973. The Interpretation of Cultures. New York: Basic Books Heryanto, Ariel. 1996. “Bahasa dan Kuasa: Tatapan Postmodernisme”, dalam

Latif, Y. dan Ibrahim, I.S. (eds.), Bahasa dan Kekuasaan: Politik Wacana di Panggung Orde Baru. Bandung: Penerbit Mizan

Heryanto, Ariel. 1996. "Pembakuan Bahasa dan Totalitarianisme" ,dalam Latif, Y. dan Ibrahim, I.S. (eds.), Bahasa dan Kekuasaan: Politik Wacana di Panggung Orde Baru. Bandung: Penerbit Mizan

Kompas, 23/3/2000

Kompas, $14 / 7 / 2000$

Kuntowijoyo. 2000. "Mitologisasi dan Mistifikasi dalam pemikiran Jawa", dalam Kompas 30/12:4

Latif, Yudi dan Ibrahim, I.S. (Eds.). 1996. "Prolog Bahasa dan Kekuasaan: Politik Wacana di Panggung Orde Baru”, dalam Latif, Y. dan Ibrahim, 1.S. (Eds.), Bahasa dan Kekuasaan : Politik Wacana di Panggung Orde Baru. Bandung: Mizan

Moedjanto, G. 1985. "Konsoljdasi Kekuasaan Dinasti Mataram Lewat Pengembangan Bahasa Jawa", Basis, No. 7-8 Tahun XXXIV

Nas, Peter J.M. 1993. "Tatanan Simbolik Jakarta: Dari Kosmos ke Kondominium", JIIS Jurnal Ilmu-llmu Sosial No.4: Perubahan Kelembagaan Menjelang Tahun 2000. Jakarta: Pusat Antar Universitas bidang IlmuIlmu Sosial Universitas Indonesia (PAU-IS-UI) dengan Penerbit Gramedia Pustaka Utama

Pabottingi, Mochtar. 1991. "Komunikasi Politik dalam Transformasi Ilmu Politik", Prisma, No. 6 Tahun XX, 6 Juni

Pabottingi, Mochtar. 1996. 'Bahasa, Politik, dan Otosentrisitas" dalam Latif, Yudi dan Ibrahim, I.S. (Eds.)., Bahasa dan Kekuasaan : Politik Wacana di Panggung Orde Baru. Bandung: Penerbit Mizan

Ramage, Douglas E. 1995. Politics in Indonesia: Democracy, Islam and the Ideology of Tolerance. London and NewYork: ROUTLEDGE Ritzer, George. 1992. Sociological Theory. McGraww-Hill INC. 
Santoso, Anang. 2001. Penggunaan Bahasa Indonesia dalam Wacana Politik. Disertasi Program Doktor Universitas Negeri Malang, Program Studi Pendidikan Bahasa

Saryono, Djoko. 1993. "Bahasa sebagai Pusat Keberadaan Manusia", Basis Edisi Maret 1993, hal 1-23.

Saryono, Djoko. 2000. "Menghormati Keberagaman, Meneguhkan Keindonesiaan: Politik Bahasa di Tengah Kemajemukan Bangsa", Makalah pada Lokakarya Politik Bahasa di Jakarta

Simon, Roger. 1999. Gagasan-Gagasan Politik Gramsci. Terj. Kamdani dan Imam Baehaqi. Yogyakarta: INSIST

Susanto, Budi. 1997. Ketoprak: The Politics of the Past in the Present Day of Java. Yogyakarta: Penerbit Kanisius

Thomas, Linda, and Shan Wareing. 1999. Language, Society and Power. New York: Routledge

Wareing, Shan. 1999. "What is language and what does it do?", in Linda, Thomas and Shan Wareing (Eds.), Language, Society and Power. London and New York: Routledge

Warsono. 2002. Wacana Politik Kiai NU pada Era Pemerintahan Gus Dur: Apakah Sebagai Intelektual Organik atau Intelektual Tradisional? Disertasi Program Pascasarjana Universitas Airlangga

Waters, Malcom. 1994. Modern Sociological Theory. London, Thousand Oaks, New Delhi: SAGE Publications

Widharyanto, B. 2000. Manifestasi Perspektif Surat Kabar Indonesia pada Akhir Era Orde Baru ke Dalam Strategi Penyajian Informasi dan Bentuk-Bentuk Ekspresi Bahasa. Disertasi Program Doktor Universitas Negeri Malang

Zada, Khamami (Ed.). 2002. Neraca Gus Dur di Panggung Kekuasaan. Jakarta: LAKPESDAM [] 